\title{
Elementary teachers' beliefs and perspectives related to smart learning in South Korea
}

\author{
Cheyeon $\mathrm{Ha}^{1^{*}}$ (D) and Soo-Young Lee ${ }^{2}$
}

\author{
* Correspondence: ch16c@my.fsu. \\ edu; cheyeonha@gmail.com \\ ${ }^{1}$ Florida State University, Stone \\ Building, 1114 W.Call St, Tallahassee, \\ FL 32306, USA \\ Full list of author information is \\ available at the end of the article
}

\begin{abstract}
This study focused on elementary teachers' perceptions of smart learning issues to suggest a better future teachers' training program to support student's smart learning in classrooms. Rapidly developing technology changes every aspect of our life. In order for twenty-first century learners to prepare for this technologically ever advancing world, teachers also should make any necessary adaptations to the changes. The use of smart devices and social networking systems is becoming more common in classrooms throughout the country. Thus, it is necessary for public schools to make appropriate changes in aspects of their technology infrastructures and instructional methods and resources for smart learning. To this end, teacher competencies are regarded as a critical factor in the successful implementation of smart learning. Smart learning is not just learning with smart devices but the learning that smart technology can afford. Prior studies have indicated that teachers' positive perceptions and knowledge of technology are associated with the successful implementation of computer-based learning. Building upon the previous research, this study investigated to what extent teachers' educational beliefs as well as teachers' positive perception, and knowledge of technology are associated with teachers' perception on smart learning. For this study, a total of 438 elementary teachers in South Korea participated in the survey on smart learning related questions including teachers' educational beliefs, technology support system in their schools, teachers' efficacy of technology-based teaching \& learning, teachers' perspective on computer-based learning and perspective on smart learning. First, the result showed that the correlations between the all measured variables were statistically significant. Then, a path analysis model of teachers' perception on smart learning was constructed, and its statistical validity was confirmed. The path model revealed that teachers' educational beliefs directly influence teachers' ICT-related knowledge and usage in the classroom. In addition, teacher's education beliefs also directly influence teachers' perception on computer-based learning and smart learning. This indicates that the smart learning shares student-centered learning beliefs. Moreover, teacher's perception on smart learning is influenced by their perception on computer-based learning, and this was in turn affected by the degree of teachers' knowledge and usage of technology. In other words, teachers who have more students-centered learning beliefs and a higher level of ICT-related knowledge and usage seemed to have a more positive view on smart learning. Also, the more technology support system school provided, the more positive perspective the teachers have on smart learning. The results of this study have implications for both pre-service and in-service teacher professional development. The (Continued on next page)
\end{abstract}


(Continued from previous page)

teachers who are responsible for the twenty-first century learners should be equipped with practical competencies of advancing technology in the classroom and firm beliefs regarding student-centered learning in technology-rich environments.

Keywords: Smart learning, Smart learning environment, E-learning, ICT in education, Teachers' beliefs, Teachers' efficacy, Teachers' perspective on smart learning

\section{Background}

Smart devices and social networking systems are becoming more common in classrooms around the country. Thus, public schools need to change aspects of their technology operating systems and instructional methods. With these changes, governments and IT companies internationally are implementing smart learning projects designed to prepare teachers for the future of education. For example, Intel and Microsoft are conducting a digital literacy study, the "Assessment and Teaching of Twenty-First Century Skills Project" (ATC21S), which is intended to improve the school curricula in Australia, Finland, Singapore, and the U.S.

In 2012, the Korean government initiated a strategic plan for SMART education for every student. SMART education is an educational policy that refers to Self-directed, Motivated, Adaptive, Resource enriched, and Technology embedded education. These are characteristics that Smart educational methods and resources should be able to offer. This addresses that Smart education is not just about education with smart devices, but it should be an educational paradigm and approach that smart technology can offer but the traditional classroom-based education had hardly afforded. To implement the SMART education policy in schools, the Korean government has developed digital textbooks, online learning resources, and infrastructure systems that allow wireless Internet connections in the school. In addition to these hardware and software-based supports, many educators and researchers have developed SMART educational models (e.g., Kim and Bae 2012; Lim et al. 2013; Noh et al. 2011), and conducted classroom-based research to find out the effectiveness of SMART education (e.g., Kim and Lee 2016; Lee and Lee 2013; Leem and Kim 2016). In addition, research on teachers' perception of Smart education have been studied with many different groups of teachers including pre-service teachers (Seol and Son 2012), in-service teachers (Lim 2012), leading teachers (Park et al. 2013), and science teachers (Yang et al. 2015). However, many of previous studies mainly focused on teachers' competencies on the technology itself or its use in the classroom and teachers' perspective on smart education. However, it is still rare to find research on teachers' beliefs about education itself either directly or indirectly affect their level of competencies of technology in the classroom and their view on smart education. If we define smart learning is not just learning with smart technology but learning that smart technology can bring about, we must pay attention to teachers' beliefs about learning itself as well as their competencies with technology.

Poulova and Klimova (2015) pointed out that the paradigm has shifted today from e-Learning to mobile learning (m-Learning); thus, "Smart learning" can be defined as a broader concept that includes both current and future technology-based learning. In general, many governments in different countries have made considerable investments 
to equip schools with technology; however, fiscal and material resources do not always result in the successful implementation of technology-enriched learning in the classroom. Previous studies on smart learning have viewed teachers as a critical factor in successful implementation of smart learning in schools (Blau and Shamir-inbal 2017; Brinkley et al. 2011; Teeroovengadum et al. 2017; Willis et al. 2018). Palfrey and Gasser (2008) described teachers and students as two very different generations. While most teachers constitute the "digital immigrants" generation that has adapted to technological development as adults, students are the "digital natives" who have been familiar with the Internet since birth. Therefore, teachers as digital immigrants require special training to educate the digital native generation. At the dawn of the twenty-first century, Roschelle et al. (2000) addressed the various ways computer technology can be used to improve how and what children learn in the classroom: "As ever-increasing resources are committed to bringing computers into the classroom, parents, policymakers, and educators need to be able to determine how technology can be used most effectively to improve student learning" (p. 77). Over the last two decades, technology has made dramatic advancements and brought astonishing changes in every aspect of our life including schools and education. We, educators, should keep studying how new technology can make learning more effective than before. In this on-going endeavor, our focus always should be the improvement of learning, which is more than just the use of technology itself.

\section{Literature review}

Development of media and technology has been accompanied by a paradigm shift in school education. Rather than learning from only teacher's lectures, many students are becoming accustomed to exploring new knowledge and expanding their learning and interests through the media. Traditional school education methods face criticism that learning content should reflect current societal trends. Therefore, teacher training programs should be improved to support the changing needs of a new generation.

Binkley et al. (2012) defined twenty-first century skills as follows: 1) creativity and innovation; 2) critical thinking, problem-solving, and decision making; 3) learning to learn and metacognition; 4) communication; 5) collaboration; 6) information literacy; 7) Information and Communication Technology (ICT) literacy; 8) citizenship; 9) life and career, and 10) personal and social responsibility. Griffin et al. (2012) also confirmed those learning skills are required in the twenty-first century; however, they believed that the skills the new generation require do not differ entirely from previous ones. Because important learning abilities are based on twentieth century technology, new technologies simply will be merged with the new learning environment based on the previous school environment.

The design of variables in the study is based on the classic Technology Acceptance Model (TAM) dimensions by Davis et al. (1989). They explained the general user's intention to accept technology with two determinants; perceived usefulness and perceived ease of use. Many recent technology user studies also develop the ideas from the TAM model (Cheok and Wong 2015; Teeroovengadum et al. 2017; Weng et al. 2018). In the same context, we assumed that when teachers have usefulness perspectives on the current computer-based teaching and learning or future smart learning, it would be 
positively related to their frequent ICT class adopting rate. Also, we took a close look at the teacher's efficacy, specifically ICT knowledge and using technology tools in classrooms. This is because teachers' perspectives of ease of use would be connected to their technology efficacy in smart learning environments.

One of the issues in smart learning in school education is that current educational methods and content do not fit well with new generation skills such as information and ICT literacy (Engen et al. 2014). Related to this problem, Boholano (2017) suggested one of the solutions would be developing a better preservice teachers' training, because they will help make a bridge between student's ICT literacy needs and the education system in the future. Hsu and Kuan (2013) mentioned that "...technology integration is influenced by many factors related to the teacher and the school environment" (p. 25). In particular, current school teachers still feel burdened in teaching effectively in the smart learning environment and supporting the skills learners expect to use in the future. Previous studies commonly supported the idea that if teachers could have a positive self-efficacy in ICT teaching and learning, they would be likely to easily adopt ICT instructions in classrooms (Blau and Shamir-inbal 2017; Chang et al. 2017; Cheok and Wong 2015; Hatlevik 2017; Holden and Rada 2011; Teeroovengadum et al. 2017; Willis et al. 2018). Moreover, Reksten (2000) explained the importance of teachers' perceptions as follows: "The critical prerequisite for successful technology integration is preparing your staff and your school community to take on the positive aspects of an inviting school 'context' for technology change" (p. 9).

In this study, teachers were assumed to be one of the most important agencies in the successful implementation of smart learning. Hereafter, in reviewing previous research on smart learning, we chose potential teacher-related variables that could affect the effective smart learning. Because previous studies have explored the relations of limited variables with small sample sizes, this study attempted to integrate teachers' knowledge and efficacy of technology use in the classroom with their beliefs about education in smart learning environments and to explore structured relations between different variables.

\section{Teachers' beliefs (TB) and smart learning}

In this study, the variable of Teachers' beliefs (TB) was classified into either learner-centered or teacher-centered, in aspects of teaching assessments and communication types (Woolley et al. 2004). The new paradigm of smart learning entails a shift toward a more individual and learner-centered approach. This is because the learner-centered approach has many benefits on a deep understanding of the key concepts during a learning process. Moreover, smart technology can provide students and teachers with learning environments that leaner-centered learning can occur. For example, it is much easier to provide individualized learning materials based on each student's needs and interests using self-paced learning tools on 1:1 tablet PC. Then, teachers can provide individualized scaffolding and feedback as they monitor and evaluate students' progress recorded in Learning Management System (LMS). Also, interactions between students- a teacher and students-students can be enhanced using a wiki or SNS systems in the classroom. Smart technology also closes a gap between the classroom and the real-world. The school curriculum can be more easily aligned with 
authentic real-world contexts as teachers and students have easier access to real-world resources including data, information, and experts than before. (Hedberg 2014). In the same context, Shim (2011) reported that those teachers who have a more student-centered view prefer to use multimedia materials in the classroom. To this end, we hypothesize that:

H1a: Teachers' belief with learner-centered view predicts their self-efficacy of ICT knowledge.

H1b: Teachers' belief with learner-centered view predicts their self-efficacy of using ICT instructions in the classroom.

H1c: Teachers' belief with learner-centered view predicts their perspectives on current computer-based learning.

H1d: Teachers' belief with learner-centered view predicts their perspectives on future smart learning.

\section{Technology support system (TSS) and smart learning}

Technology Support System (TSS) has been recognized as one of the most important variables in national school education reform policies. Because many smart learning policies are based on building a better smart learning environments, policymakers believe that they should have sufficient budgets. The study of AT21CS also began with the support from renowned IT companies such as Microsoft, Intel, and Cisco. Schools undergo slow system changes compared to other fields. The TSS variable was selected according to these social conventions, in that if a school has a better technology support system, teachers will have positive perceptions about smart learning instruction. Technology Support System is not just technological infrastructure but should also include supports from administrators, technicians and other teachers in the school. In connection with this, van Braak et al. (2004) showed that the most meaningful predictor of teachers' computer use was technological innovation in the classroom environment. In another prior study, Petko (2012) reported that using diverse media and offering frequent opportunities for students' learning activities in the classroom could improve students' understanding and lead to greater academic achievement. In this context, we hypothesize that:

H2a: Technology support system in schools predicts teachers' self-efficacy of ICT knowledge.

H2b: Technology support system in schools predicts teachers' self-efficacy of using ICT instructions in the classroom.

H2c: Technology support system in schools predicts teachers' perspectives on current computer-based learning.

H2d: Technology support system in schools view predicts teachers' perspectives on future smart learning.

\section{Teachers' efficacy of technology based teaching-learning (TETBTL)}

The variable of Teachers' Efficacy of Technology Based Teaching-Learning (TETBTL) was analyzed as a contributing factor to increase the expectations of smart learning. Efficacy refers to an individual's confidence in his/her ability to perform a task. We measured teachers' efficacy with respect to TETBTL with two sub-factors: 1) knowledge of 
technology, and 2) use of technology in the classroom. Hsu and Kuan (2013) stated that, regardless of their professional teaching ability, some obstacles may slow the progress of changes in the classroom, such as teachers' preferences to teach through lectures and negative perceptions about using technological tools. Holden and Rada (2011) explained the relationship between a teacher's technology efficacy and tendency to accept technology. In similar prior studies, teachers who believe the new media tools have more educational benefits are more likely to use them. And their high degree of technology tool use was positively related to students' academic achievement (Albirini 2006; van Braak et al. 2004). Based on these ideas, we propose the following hypotheses:

H3a: Teachers' self-efficacy of ICT knowledge predicts their perspectives on current computer-based learning.

H3b: Teachers' self-efficacy of ICT knowledge predicts their perspectives on future smart learning.

H3c: Teachers' self-efficacy of using ICT instructions in the classroom predicts their perspectives on current computer-based learning.

H3d: Teachers' self-efficacy of using ICT instructions in the classroom predicts their perspectives on future smart learning.

\section{Perspective on computer-based learning (PCL)}

This variable measure teacher's current perspectives on computer-based learning. Although the shift to a smart learning environment has been quite slow in schools, most schools already have computers in the classroom, and also use them frequently as a common instructional tool. Holden and Rada (2011) stated that teachers who have a more positive perception of ICT usefulness tend to take advantage of technological tools more actively. Therefore, we assumed that current teachers' computer use, and positive perception could be linked to the future instructional use of smart technology such as tablets, virtual reality system, and other communicative social media devices. Accordingly, we suggest the following hypotheses:

H4: Teachers' perspectives on current computer-based learning predicts their perspectives on future smart learning.

\section{Perspective on smart learning (PSL)}

This variable is a dependent variable of this study as this is closely related to the core of the study. PSL is a teachers' attitude and belief toward smart learning, and it was assumed to be related to other variables in this study.

Holden and Rada (2011) constructed a model of teachers' tendencies to accept technology. They explained that teachers' technology efficacy is associated with the usability of technology and that usability is related to perceived usefulness. Many teachers are reluctant to make changes and use new technology and innovation in the classroom when they feel they lack the skills to do so and prefer the traditional teaching methods they are familiar with. Brinkley et al. (2011) found that it is quite difficult for teachers to use teaching methods to which they are not accustomed, such as using electronic resources in teaching. Other researchers have focused on teachers' 
negative views about technology-based learning assessments (e.g., Inan and Lowther 2010; Lowther et al. 2008).

This correlational study defined the variables related to teachers' perspectives on smart learning and investigated the relations among them in the current school environment in Korea. The study results led to suggestions about an effective teachers' training program model to be addressed in a follow-up study.

\section{Methods}

We investigated to what extent teachers' educational beliefs (TB), technology support system (TSS) in the school, teachers' self-efficacy on knowledge of technology (ICT-K) and self-efficacy on use of technology in the classroom (ICT-U) influence teachers' perceptive on computer-based learning (PCL) as well as perspective on smart learning (PSL). This study first sought to explain the correlations among the measured variables related to teachers' perspectives on smart learning. Then, the path model with those variables was constructed and confirmed.

\section{Survey research design}

Survey research has various strengths because it can efficiently gather and capture meaningful information on participants' perspectives, characteristics, and actions from a large sample (Pinsonneault and Kraemer 1993). The sampling plan reflected the study's purpose, which was to explore current elementary teachers' perspectives on smart learning and other psychological and behavioral variables. We sampled 20 different elementary schools in an urban area of South Korea randomly and collected written surveys from more than 400 teachers. Aron et al. (2008) stated that the effect size provides information in survey research by indicating the importance of the study results overall. In the study, a medium effect size, .30, was selected. To increase statistical power, the sample was larger than that recommended at the power baseline of .90 and $\alpha$ level of .05.

\section{Measurements}

The survey instrument comprised of five sections: TB, TSS, TETBTL (ICT-K \& ICT-U), PCL, and PSL. The TB showed whether teachers' educational beliefs tended closer to either a teacher- or student-centered learning. The second variable, the TSS in schools was about teachers' perception on how much they had the necessary technology supports in their school environments. The next variable used was TETBTL, which has two subscales: 1) Knowledge of Information \& Communication Technology (ICT-K), and 2) Use of Information \& Communication Technology in the classroom (ICT-U). The PCL variable was selected to investigate teachers' current understanding of computer use in the classroom. The last variable was PSL, which was the core of the study. PSL was about teachers' concerns as well as expectations regarding smart learning can bring about in the classroom. We explored to what degree PSL could be affected by previously described independent variables. TB was assessed with a total of 29 questions that addressed teachers' constructivist views of the classroom. The first part of TB was asking to what degree participants agree to a teacher's role to be either facilitator or lecture. The second part of TB was tapped into teachers' beliefs regarding 
learning in general (e.g., A good quality of teaching class depends on each student's learning). A low score on TB indicates a teacher-centered perspective, while a high score indicates that the teacher tends to adopt a student-centered approach. The questions were taken from Woolley et al.'s (2004) study. The authors reported the Cronbach's $\alpha$ of TB was .78.

The TSS comprised 13 questions on a 5-point Likert scale, that asked about the schools' technological system and support status. Teachers answered the questions from 1 (I totally disagree with that) to 5 (I totally agree with that). The items evaluated participants' current working school environment (e.g., I think that the current school environments provide appropriate technical support for ICT instructions). The survey questions were selected from Shin's (2011) study of ICT teachers' instruction, in which he reported that the instrument's final Cronbach's $\alpha$ was .92 .

The TETBTL had two subscales. The questions were taken from Pepanastasiou and Angeli (2008) study, which evaluated teachers' ICT-K and ICT-U on a 5-point Likert scale; they reported that the Cronbach's reliabilities of the two were .83 and .88 , respectively. Based on prior ICT research, the questions were adjusted to expand the meaning to include the concept of smart learning. For example, prior study questions asked about the use of desktop computer-based tools; however, the revised questions included broader technological tools and Smartphone applications, such as Chat, Facebook, and Twitter. Therefore, 10 questions were used to evaluate teachers' efficacy about current knowledge (e.g., I know how I can help students when they have some problems using ICT tools), and 18 items measured teachers' efficacy in ICT use in the classroom (e.g., I can use ICT tools for data collection, data analysis, and sharing the analyzed data results).

The PCL measure was reconstructed from the questionnaire on teachers' attitudes Pepanastasiou and Angeli (2008) used in their study, which included a total of 23 questions on a 5-point Likert scale. The participants responded to the answer ranging from 0 (I cannot do it at all) to 5 (I totally can do it all). The items measured teachers' perceptions on current computer-based learning in schools (e.g., Using ICT in a classroom helps teachers teaching students with more effective ways).

The PSL questionnaire measured the degree of positive expectations teachers have about smart learning's effectiveness in the classroom. The contents addressed the general use of computers and diverse devices. Prior studies of ICT and Technology-based learning were reviewed to develop the questionnaire, and a total of 37 questions was included in the final instrument. The items measured teachers' perceptions of future smart learning in schools (e.g., I believe that future schools need to be changed into smart learning environments for teaching and learning innovation). The participants responded to the 5-point Likert scales questions from 1 (I totally disagree with that) to 5 (I totally agree with that).

\section{Data sources and analysis}

The paper-based survey was administered to elementary teachers $(n=438)$ in 20 different public elementary schools in Seoul and Gyeonggi, located in an urban area of South Korea. After missing and non-response cases were eliminated, data from 398 teachers were finally included in the analyses. 
The study used a quantitative correlational design to explore the diverse relations between PSL and the other teacher variables. Pearson correlations between the six variables were tested.

The data were analyzed with SPSS (v. 23.0) and Mplus (v. 8). The Pearson correlation coefficient was used in the correlation analyses, and then the path model of PSL used the standardized coefficients in Mplus.

\section{Results}

As Table 1 shows, all variables in the study were strongly correlated each other ( $p$ $<.001)$. Specifically, PSL was the key variable to be predicted and could be explained according to its relations with the other variables in the study.

The results demonstrated that elementary teachers' PCL was positively associated with PSL $(p<.001)$. Student-centered beliefs $(p<.001)$ and TSS $(p<.001)$ were correlated with PSL, and both the teachers' efficacy in ICT-K and ICT-U were also correlated with PSL $(p<.001)$. Because TB, TSS, ICT-K, ICT-U, and PCL were correlated with PSL, it was assumed that existing teachers' and systems' variables could explain teachers' positive perceptions of smart learning in schools. After confirming the correlational relationships between the five independent variables and the dependent variable, PSL, causal relations between variables were explored using the path analysis. The path model goodness-of-fit depends on the results of a Chi-squared test of the model fit $\left(x^{2}\right)$, the RMSEA, the range of CI, CFI, TFI, and SRMR (Kline 2015). The constructed model fit the data well $\left(\chi^{2}(4)=3.79, p=.44\right.$, RMSEA $=.000,90 \%$ CI $[0.000,0.07] \mathrm{CFI}=$ 1.000 , TFI $=1.001$, SRMR $=.01$ ). The path model (Fig. 1) with standardized coefficients shows the diverse direct and indirect effects of the independent variables on PSL. The power of the goodness-of-fit test was greater than .95 with the sample size of 398, and $\alpha$ error probability of .05.

Student-centered TB showed influence on all the other variables in the study. Thus, TB is an important variable that can predict current teachers' efficacy with technology and teachers' perception on computer-based learning and smart learning. TSS were related to teachers' efficacy of ICT-K and ICT-U, PCL, and the outcome variable, PSL ( $p$ $<.05$ for all). Therefore, establishing good technology systems in schools enhances teachers' efficacy with respect to ICT and increases their positive perceptions of smart learning. Teachers who believed they understand technology well were likely to believe they could use it in the classroom more effectively $(p<.05)$.

Table 1 Correlations Among the Variables of Teachers' Perspectives on Smart Learning

\begin{tabular}{|c|c|c|c|c|c|c|}
\hline Pearson Correlation & $\mathrm{TB}$ & TSS & $\mathrm{ICT}-\mathrm{K}$ & $\mathrm{ICT}-\mathrm{U}$ & $\mathrm{PCL}$ & PSL \\
\hline $\mathrm{TB}$ & 1 & & & & & \\
\hline TSS & $0.22^{* * *}$ & 1 & & & & \\
\hline $\mathrm{ICT}-\mathrm{K}$ & $0.27^{* * *}$ & $0.28^{* * *}$ & 1 & & & \\
\hline ICT-U & $0.28^{* * *}$ & $0.29^{* * *}$ & $0.78^{* * *}$ & 1 & & \\
\hline$P C L$ & $0.26^{* * *}$ & $0.17^{* * *}$ & $0.33^{* * *}$ & $0.37^{* * *}$ & 1 & \\
\hline PSL & $0.28^{* * *}$ & $0.32^{* * *}$ & $0.22^{* * *}$ & $0.28^{* * *}$ & $0.58^{* * *}$ & 1 \\
\hline
\end{tabular}

Note. Variable explanations. (TB Teacher's Beliefs, TSS Technology Support System, ICT-K Teacher's efficacy of ICT Knowledge, ICT-U Teacher's efficacy of ICT Using technology in the classroom, PCL Perspective on Computer-based Learning, PSL Perspective on Smart Learning) ${ }^{*} p<.05 .{ }^{* *} p<.01 .{ }^{* * *} p<.001$ 


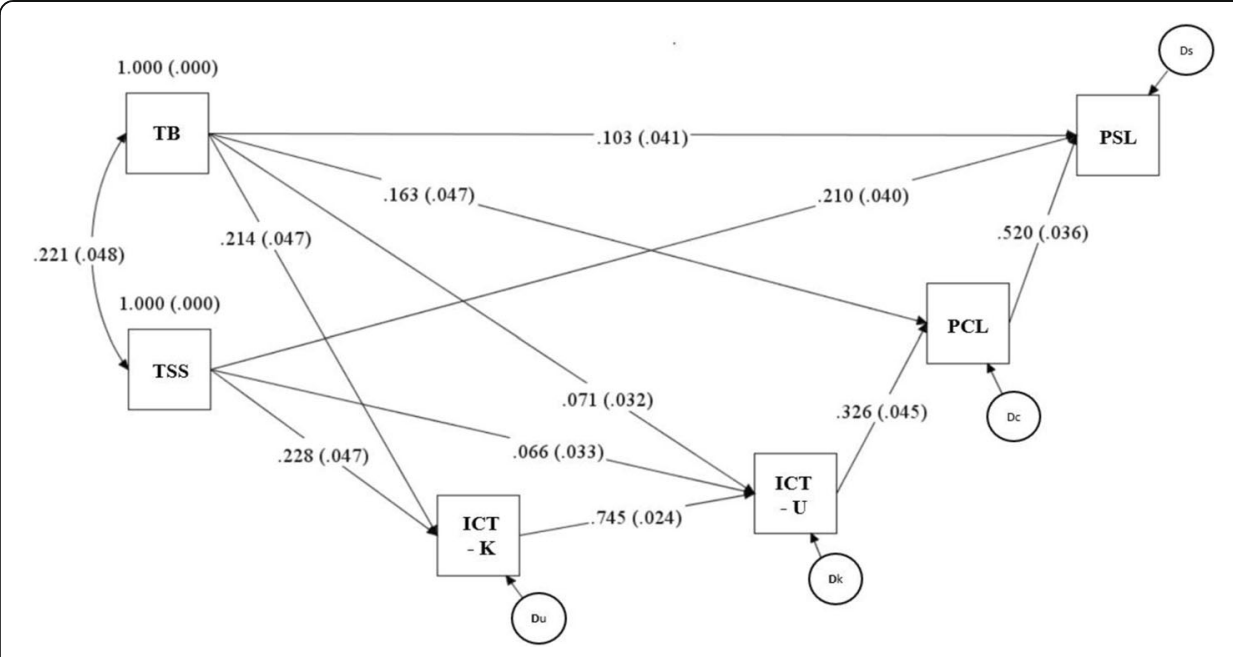

Fig. 1 A path model of PSL. Note. Standardized coefficients, $p$-values, and SEs are shown

Further, teachers who were confident about their ability to use technology exhibited more positive perceptions about computer-based teaching and learning in schools ( $p$ $<.05)$. The teachers with a more positive view on computer-based learning tended to have more positive expectation regarding smart learning as well. Moreover, student-centered TB, TSS, and teachers' positive PCL $(p<.05$ for all) had direct effects on the predicted outcome of PSL in addition to indirect impacts via other mediated variables.

We concluded that successful smart learning in schools requires a shift in teachers' educational beliefs to student-centered learning, and efforts to build better technological systems in schools. Moreover, the degree of teachers' self-efficacy on knowledge of ICT and use of ICT in the classroom could predict the state of teachers' perception on computer-based learning, and it will be eventually able to affect teachers' perception on smart learning. Efforts to increase the frequency of computer-based teaching and learning in current classrooms will also contribute to positive perceptions about smart learning in the future. The teachers who have more student-centered educational beliefs with a higher degree of technology support in the school tend to have a more positive view on smart learning. The teachers who believe that they have sufficient knowledge of technology tend to use technology more confidently in the classroom, and they tend to have a more positive view on the effectiveness of computer-based learning and smart learning. Therefore, we suggest that pre-service and in-service professional development programs address all these complex aspects that can affect teachers' concerns and expectations regarding smart learning.

\section{Discussion and conclusion}

This study is a meaningful step in addressing smart learning in public education. Through the study, we explored the diverse variables associated with teachers' perspectives on smart learning. Although policymakers have invested considerable budgets in schools to build better technology infrastructure, smart learning has not fully implemented in real schools. The schools and classrooms have been making changes as technology progresses. Nonetheless, all the promises the smart learning has been trying to 
deliver in the classrooms are not entirely prominent yet, because technology alone can't bring about changes in students' learning. Building upon the previous studies on teachers' critical role in successful implementation of computer-based learning, we tried to find out complex relationships among teacher variables which would contribute to effective smart learning.

In our study, we surveyed a total of 438 elementary teachers from 20 randomly sampled schools in South Korea. Pearson correlation analysis and path analysis were conducted to explored complex relations among the measured variables. In our analysis, we found that student-centered teacher belief was associated directly with teachers' efficacy in ICT-K and ICT-U. Also, this study supports the previous study results that teachers with a student-centered view showed more positive perspectives on current computer-based learning as well as future smart learning (Shim 2011). This indicates that it is most important for teachers to believe that effective learning occurs when students can construct their knowledge and understanding, and when teachers facilitate the learning process and provide an appropriate learning environment. Then, the teachers who have this student-centered learning view would accommodate technology for the sake of students' learning. Those teachers will regard smart technology as just another tool for learning rather than the new technology itself, and they will draw their attention to what the new technology can offer for students' learning instead of what the new technology is (Holden and Rada 2011; Inan and Lowther 2010; Lowther et al. 2008). This means that the future pre-service and in-service professional development for smart learning should address the fundamental issues with leaning. Teachers should be able to have a chance to explore characteristics of effective leaning environments first, then they can investigate what smart technology can do to make effective learning environments. Once teachers see what and how new technology can offer to make effective learning environments, they can be motivated to adopt new technology for learning purpose.

We also found that technology support system is an important variable associated with teachers' efficacy in ICT-K and ICT-U. This supports the results of prior research that technological innovation in the classroom is key to realize successful smart learning (van Braak et al. 2004). This indicates that investment in better technology support systems is related directly to teachers' efficacy in technology-based teaching and learning. Thus, policymakers can expect increased teacher efficacy through appropriate investments in technology support systems. Although technology support system was not directly related to the frequent implementation of current computer-based learning in the classroom, teachers who work in an environment with a better technology system tend to have more positive perceptions of future smart learning. The technology support system is not just infrastructure but also include human supports from administrators, technicians and other colleagues. When teachers feel they can get necessary technical, emotional, and environmental supports while they are implementing smart learning, they will more likely adapt new technology in the classroom. When teachers feel they are not alone and further they are encouraged to make changes in the school, they are willing to take a risk. Establishing and providing appropriate and continuous technical support system take time and budget. It requires systematic changes across the school. All constituents of the school should share the vision and expected 
outcomes of smart learning. While there are many cost and time constraints to build a smart learning system, providing smart learning training would help teachers to prepare new teaching and learning resources in smart environments.

Consistent with prior studies (Albirini 2006; Blau and Shamir-inbal 2017; Chang et al. 2017; Hatlevik 2017), our study found that teachers who have more positive perspectives on current computer use in teaching and learning are likely to have positive perspectives on future smart learning as well. Therefore, it is necessary for teachers to have positive experiences with technology-based teaching and to learn even with a very simple tool based on the recent TAM model studies (Cheok and Wong 2015; Weng et al. 2018). Developing and implementing new tools and materials in learning environments can be challenging for teachers. Teachers who had difficulties and obstacles in using new tools or technology are hard to try another emerging technology. Thus, teacher professional development programs should increase teachers' positive experiences and decrease the possible risk of failure using new technology. To do so, professional development programs should reflect the teachers' voice and needs.

Consequently, to create a stable foundation for a successful smart learning environment in the schools, policymakers and administrators need to support teachers and encourage them to use computers and other emerging technology in the classroom. Those supports involve changing curricula from traditional lecture to more student-centered interactive classes. This study shows the way in which teachers' psychological variables have profound associations with the successful implementation of smart learning in real-world classes.

\section{Limitations and recommendations for future studies}

The data in this study were collected from urban areas in South Korea, and a total of 398 teacher surveys was analyzed to obtain the results. However, the study results could include a potential bias that precludes their generalization to the entire population. For example, teachers in suburban or rural areas with lower investments in technology may have different perceptions from those of teachers in urban areas. Further, the participants' nationality or their different cultural environment could have affected their responses compared to those of teachers in European countries or the U.S. Although these are potential effects of the sampling scheme, South Korea is among the countries most responsive to changes in the IT technology environment. Therefore, there is a high demand for teacher training programs to effect these technological, environmental changes.

Further, the teachers in Korea are required to take professional development training when there is a change in educational policy to learn alternatives to their traditional teaching skills. This is in common with other countries that have undergone changes in the smart learning environment in schools. Therefore, diagnosing problems and the perceptions of South Korean teachers who are adapting to new teaching methods in a smart learning environment can present significant implications for many other countries that will experience similar changes.

The study was an exploratory study that investigated current teachers' perceptions about smart learning, but at the same time, it also was designed to be used as a basic 
resource to develop smart learning teacher training programs that reflect teachers' needs. Therefore, future studies should focus on identifying practical ways to train teachers in the smart learning environment, as improving teaching competence is an important topic in school education. Our follow-up study will address more practical subject learning issues in classrooms related to diverse, smart learning content and technology in the classroom.

\section{Acknowledgements}

This study was invited to be presented at the roundtable session, "Science instructor's technology use" at the 2018 AERA conference.

\section{Funding}

Not applicable.

\section{Availability of data and materials}

Not applicable.

\section{Authors' contributions}

$\mathrm{CH}$ carried out the design of the study, data analysis processes and drafted the manuscript. She participated at 2018 AERA discussion session as a presenter with the study process. SL performed the design survey instruments,data collect, and data collection coordination. She also contributed to providing profound references for the literature review and research background. Both authors read and approved the final revised manuscript.

\section{Authors' information}

Cheyeon $\mathrm{Ha}$ is a doctoral student in Educational Psychology and Learning System, Florida State University. Her current research interests include teachers' efficacy, teachers' training programs, and effective teaching and learning. Sooyoung Lee is an Associate Professor in the Department of Elementary Education at the Seoul National University of Education. Her current research interests include effective multimedia use in classrooms, smart learning issues in elementary education, and the development of teachers' training programs.

\section{Ethics approval and consent to participate}

The study was conducted on Korean teachers. By the national education research policy of South Korea, the ethics committee's approval process were waived. All participants in the study were adults, they were guided about the purpose of the study before the start of the questionnaire. The In the study, data were analyzed only the with participants consents on data collections.

\section{Consent for publication}

Not applicable.

\section{Competing interests}

The authors declare that they have no competing interests.

\section{Publisher's Note}

Springer Nature remains neutral with regard to jurisdictional claims in published maps and institutional affiliations.

\section{Author details}

${ }^{1}$ Florida State University, Stone Building, 1114 W.Call St, Tallahassee, FL 32306, USA. ${ }^{2}$ Seoul National University of Education, 96, Seochojungang-ro, Seocho-gu, Seoul, Republic of Korea06639.

Received: 21 September 2018 Accepted: 7 January 2019

Published online: 12 February 2019

\section{References}

A. Albirini, Teachers' attitudes toward information and communication technologies: The case of Syrian EFL teachers. Comput. Educ. 47(4), 373-398 (2006). https://doi.org/10.1016/j.compedu.2004.10.013.

A. Aron, E. Aron, E.J. Coups, Statistics for the Behavioral and Social Sciences: A Brief Course (Pearson Prentice Hall, Upper Saddle River, 2008)

M. Binkley, O. Erstad, J. Herman, S. Raizen, M. Ripley, M. Miller-Ricci, M. Rumble, in Assessment and Teaching of 21st Century Skills. Defining twenty-first century skills (Springer, Netherlands, 2012), pp. 17-66. https://doi.org/10.1007/978-94-0072324-5_2.

I. Blau, T. Shamir-inbal, Digital competences and long-term ICT integration in school culture: The perspective of elementary school leaders. Educ. Inf. Technol. 22(3), 769-787 (2017). https://doi.org/10.1007/s10639-015-9456-7.

H.B. Boholano, Smart social networking: 21st century teaching and learning skills. Res. Pedagogy 7(1), 21-29 (2017). https:// doi.org/10.17810/2015.45.

A. Brinkley, E. El-Fakahany, B. Dessants, M. Flamm, C.B. Forcey Jr., M.L. Ouellett, E. Rothschild, The Chicago handbook for teachers: A practical guide to the college classroom (University of Chicago Press, Chicago, 2011). 
H.H. Chang, C.S. Fu, C.Y. Huang, Willingness to adopt or reuse an E-learning system: The perspectives of self-determination and perceived characteristics of innovation. Innov. Educ. Teach. Int. 54(5), 511-520 (2017). https://doi.org/10.1080/ 14703297.2016.1194768.

M.L. Cheok, S.L. Wong, Predictors of E-learning satisfaction in teaching and learning for school teachers: A literature review. Int. J. Instr. 8(1), 75-90 (2015).

F. Davis, R. Bagozzi, P. Warshaw, User acceptance of computer technology: A comparison of two theoretical models. Manag. Sci. 35(8), 982-1003 (1989).

B.K. Engen, T.H. Giæver, L. Mifsud, Mind the gap: ICT in the Norwegian national curriculum and the 2010 Teacher Education Reform. Paper presented at the Nordic Educational Research Association (NERA) conference (Education for sustainable development, Lillehammer, 2014).

P. Griffin, E. Care, B. McGaw, in Assessment and Teaching of 21st Century Skills. The changing role of education and schools (Springer, Dordrecht, 2012), pp. 1-15. https://doi.org/10.1007/978-94-007-2324-5_1.

O.E. Hatlevik, Examining the relationship between teachers' self-efficacy, their digital competence, strategies to evaluate information, and use of ICT at school. Scand. J. Educ. Res. 61(5), 555-567 (2017). https://doi.org/10.1080/00313831.2016.1172501.

J.G. Hedberg, Extending the pedagogy of mobility. Educ. Media Int. 51(3), 237-253 (2014). https://doi.org/10.1080/09523987. 2014.968447.

H. Holden, R. Rada, Understanding the influence of perceived usability and technology self-efficacy on teachers' technology acceptance. J. Res. Technol. Educ. 43(4), 343-367 (2011). https://doi.org/10.1080/15391523.2011.10782576.

S. Hsu, P.Y. Kuan, The impact of multilevel factors on technology integration: The case of Taiwanese grade 1-9 teachers and schools. Educ. Technol. Res. Dev. 61(1), 25-50 (2013). https://doi.org/10.1007/s11423-012-9269-y.

F.A. Inan, D.L. Lowther, Factors affecting technology integration in K-12 classrooms: A path model. Educ. Technol. Res. Dev. 58(2), 137-154 (2010). https://doi.org/10.1007/s11423-009-9132-y.

D.Y. Kim, S.Y. Lee, A study on the effect of the usage of smart education tools on attention and study achievement of learners: Application cases of Korean language courses in elementary school. Korean J. Elementary Educ. 27(2), 141-159 (2016). https://doi.org/10.20972/kjee.27.2.201606.141.

M. Kim, Y. Bae, Development of a smart education model for field application of smart education. J. Internet Comput. Serv. 13(5), 77-92 (2012). https://doi.org/10.7472/jksii.2012.13.5.77.

R.B. Kline, Principles and Practice of Structural Equation Modeling, 4th edn. (Guilford Press, New York, 2015).

E. Lee, J.Y. Lee, Analysis of structural relationships of learner characteristics, interactions flow, perceived usefulness and learning satisfaction in SMART education environments: Focused on elementary school. J. Educ. Inf. Media 19(3), 573-603 (2013).

J. Leem, S. Kim, Effects of flipped learning on learning achievement, collaboration ability, and ICT literacy in smart learning environment. J. Educ. Technol. 32(4), 809-836 (2016). https://doi.org/10.17232/KSET.32.4.809.

B. Lim, Analysis of the elementary school teachers' needs on digital textbooks and its implications on the policy making. Korean J. Educ. Technol. 28(2), 317-346 (2012). https://doi.org/10.17232/KSET.28.2.317.

B.R. Lim, J.H. Leem, E.M. Sung, What is the concept of smart education and the typology of smart education contents. J. Educ. Technol. 29(3), 459-489 (2013). https://doi.org/10.17232/KSET.29.3.459.

D.L. Lowther, F.A. Inan, J.D. Strahl, S.M. Ross, Does technology integration "work" when key barriers are removed? Educ. Media Int. 45(3), 195-213 (2008). https://doi.org/10.1080/09523980802284317.

K.S. Noh, S.H. Ju, J.T. Jung, An exploratory study on concept and realization conditions of smart learning. J Dig. Convergence 9(2), 79-88 (2011). https://doi.org/10.14400/JDPM.2011.9.2.079.

J. Palfrey, U. Gasser, Born Digital: Understanding the First Generation of Digital Natives (Basic Books, New York, 2008).

S.H. Park, K. Lim, J.Y. Lee, Analyses on the differences in the perception of job responsibility between "smart education" leading teachers and regular teachers using the IPA technique. Stud. Educ. Info. Media 2(19), $201-227$ (2013) Retrieved from http://kiss.kstudy.com/thesis/thesis-view.asp?key=3177280.

E.C. Pepanastasiou, C. Angeli, Evaluating the use of ICT in education: Psychometric properties of the survey of factors affecting teachers teaching with technology (SFA-T ${ }^{3}$ ). Educ. Technol. Soc. 11(1), 69-86 (2008) Retrieved from https:// www.researchgate.net/publication/220374660_Evaluating_the_Use_of_ICT_in_Education_Psychometric_Properties_of_ the_Survey_of_Factors_Affecting_Teachers_Teaching_with_Technology_SFAT3.

D. Petko, Teachers' pedagogical beliefs and their use of digital media in classrooms: Sharpening the focus of the 'will, skill, tool'model and integrating teachers' constructivist orientations. Comput. Educ. 58(4), 1351-1359 (2012). https://doi.org/ 10.1016/j.compedu.2011.12.013.

A. Pinsonneault, K. Kraemer, Survey research methodology in management information systems: An assessment. J. Manag. Inf. Syst. 10(2), 75-105 (1993). https://doi.org/10.1080/07421222.1993.11518001.

P. Poulova, B. Klimova, Smart learning: Are we ready for it? Int. Assoc. Dev. Inf. Soc., 341-346 (2015) Retrieved from https:// eric.ed.gov/?id=ED562114.

L.E. Reksten, Using Technology to Increase Student Learning (Corwin Press, Thousand Oaks, 2000).

J.M. Roschelle, R.D. Pea, C.M. Hoadley, D.N. Gordin, B.M. Means, Changing how and what children learn in school with computer-based technologies. Futur. Child. 10(2), 76-101 (2000) https://psycnet.apa.org/record/2001-00892-003.

M.G. Seol, C.I. Son, A survey on teacher's perceptions about the current state of using smart learning in elementary schools. Korean Assoc. Info. Educ. 16(3), 309-318 (2012) Retrieved from http://www.ndsl.kr/ndsl/commons/util/ndslOriginalView. do?cn=JAKO201206737753551\&dbt=JAKO\&koi=KISTI1.1003\%2FJNL.JAKO201206737753551.

S.Y. Shim, Relation between teachers' constructivism and attitudes and competence ICT in early childhood classrooms. J. Korean Counc. Child. Rights 14(1), 109-128 (2011) Retrieved from https://www.kci.go.kr/kciportal/ci/sereArticleSearch/ ciSereArtiView.kci?sereArticleSearchBean.artild=ART001426905.

W.S. Shin, Factors influencing elementary school teachers' ICT instruction. J. Korean Assoc. Educ. Info. Media 17(2), 239-260 (2011) Retrieved from http://uci.kci.go.kr/resolution/result.do?res_cd=G704-000427.2010.14.1.006\&res_svc_cd=.

V. Teeroovengadum, N. Heeraman, B. Jugurnath, Examining the antecedents of ICT adoption in education using an extended technology acceptance model (TAM). Int. J. Educ. Dev. Info. Commun. Technol. 13(3), 4-23 (2017) Retrieved from https:// search.proquest.com/openview/2df33692642e8c720569bf7c53384821/1?pq-origsite=gscholar\&cbl=28521.

J. van Braak, J. Tondeur, M. Valcke, Explaining different types of computer use among primary school teachers. Eur. J. Psychol. Educ. 19(4), 407-422 (2004). https://doi.org/10.1007/BF03173218. 
F. Weng, R.J. Yang, H.J. Ho, H.M. Su, A TAM-based study of the attitude towards use intention of multimedia among school teachers. Appl. Syst Innov. 1(3), 36-44 (2018). https://doi.org/10.3390/asi1030036.

R.L. Willis, D. Lynch, P. Fradale, T. Yeigh, Influences on purposeful implementation of ICT into the classroom: An exploratory study of K-12 teachers. Educ. Inf. Technol., 1-15 (2018). https://doi.org/10.1007/s10639-018-9760-0.

S.L. Woolley, W.J.J. Benjamin, A.W. Woolley, Construct validity of a self-report measure of teacher beliefs related to constructivist and traditional approaches to teaching and learning. Educ. Psychol. Meas. 64(2), 319-331 (2004). https:// doi.org/10.1177/0013164403261189

C. Yang, M. Jo, T. Noh, Investigation of teaching practices using smart technologies and science teachers' opinion on their application in science education. J. Korean Assoc. Res. Sci. Educ. 35(5), 829-840 (2015). https://doi.org/10.14697/jkase. 2015.35.5.0829.

Submit your manuscript to a SpringerOpen ${ }^{\circ}$ journal and benefit from:

- Convenient online submission

- Rigorous peer review

- Open access: articles freely available online

High visibility within the field

Retaining the copyright to your article 